\title{
Detection of Two Peronospora spp., Responsible for Downy Mildew, in Opium Poppy Seed
}

Tamilarasan Thangavel, Tasmanian Institute of Agriculture (TIA), University of Tasmania, New Town, Tasmania 7008, Australia; Suzanne Jones and Jason B. Scott, TIA, University of Tasmania, Burnie TAS 7320, Australia; Mark Livermore, Tasmanian Alkaloids Pty Ltd, P.O. Box 130, Westbury, TAS 7303, Australia; and Calum R. Wilson, ${ }^{\dagger}$ TIA, University of Tasmania, New Town, Tasmania 7008 , Australia

\begin{abstract}
Downy mildew is a serious threat to opium poppy production globally. In recent years, two pathogen species, Peronospora somniferi and Peronospora meconopsidis, which induce distinct symptoms, have been confirmed in Australia. In order to manage the spread of these pathogens, identifying the sources of inoculum is essential. In this study, we assessed pathogen presence associated with poppy seed. We developed PCR and qPCR assays targeting the coxI and coxII gene regions, for the detection, differentiation, and quantification of $P$. somnifer and $P$. meconopsidis in poppy seed. These results were complemented and compared with direct seed histological examination and a seed washing combined with viability staining for oospore detection. The majority of seed lots from all harvest years contained detectable P. meconopsidis, the earliest (1987) predating the first official record of the disease

in Tasmania (1996). In contrast, only seed lots harvested in 2012 or later contained P. somniferi, evidence of its more recent introduction. P. meconopsidis contamination was estimated to be as high as $33.04 \mathrm{pg}$ DNA/g of seed and P. somniferi as high as $35.17 \mathrm{pg} \mathrm{DNA} / \mathrm{g}$ of seed. Incidence of pathogen contamination of seeds, estimated via a group testing protocol, ranged from 0 to $9 \%$ (P. meconopsidis) or 0 to $11 \%$ (P. somniferi). Mycelia were predominately found external to the seed coat. Seed washing and viability staining demonstrated that putatively viable oospores were present in the majority of seed lots. Transmission testing confirmed both pathogens can be successfully transmitted from infested seed to infected seedling. PCR and qPCR pathogen assays were found to be reliable and offer a routine test for determining pathogen inoculum in poppy seeds.
\end{abstract}

Opium poppy (Papaver somniferum) is a highly valuable crop grown for its opiate alkaloid content: primarily morphine, thebaine, and codeine (Levy and Milo 1998; Fist and Chung 2015). Australia is the world's largest producer of licit opiates, providing approximately $50 \%$ of global supply, with an estimated farm gate value in 2016 of AU $\$ 100$ million (Thangavel et al. 2017). Australian poppy production is predominantly based in the state of Tasmania; however, recent trials and commercial production have commenced in other Australian states and territories.

Since the first Australian record in 1996 (Cotterill and Pascoe 1998), downy mildew has been a constant constraint to Australian poppy production. At that time, downy mildew was characterized by dark localized angular foliar lesions, delimited by leaf veins, with white downy growth of conidiophores on the abaxial leaf surfaces (Scott et al. 2003). The causal agent of this disease was initially described as Peronospora arborescens (Cotterill and Pascoe 1998). However, subsequent studies suggested that the pathogen infecting poppy crops was Peronospora cristata (Scott et al. 2004). A revision of Peronospora spp. associated with poppy downy mildew has again reclassified this pathogen as another species, P. meconopsidis (Voglmayr et al. 2014). Since the 2013-14 growing season, in addition to plants showing typical localized lesions, downy mildew affected plants showing systemic invasion have been commonly observed in Australian crops. Systemically infected plants are stunted with

\section{${ }^{\dagger}$ Corresponding author: C. R. Wilson; E-mail: calum.wilson@utas.edu.au}

Funding: This study was supported by the Australian Government through the Australian Research Council Linkage funding scheme (project LP160100758), with co-investments from Tasmanian Alkaloids Pty Ltd, SunPharma Pty Ltd, The Poppy Growers of Tasmania and the Tasmanian Department of Primary Industry Water and Environment.

*The $\boldsymbol{e}$-Xtra logo stands for "electronic extra" and indicates that three supplementary tables are published online.

Accepted for publication 26 April 2018.

(c) 2018 The American Phytopathological Society chlorotic distorted leaves on which profuse pathogen sporulation is observed. These systemic symptoms were confirmed to be associated with a second downy mildew pathogen, Peronospora somniferi (Thangavel et al. 2017). P. somniferi has previously been reported from European and Asian poppy crops exhibiting similar symptoms (Voglmayr et al. 2014). Both P. somniferi and P. meconopsidis occur widely throughout poppy growing regions of Asia and Europe (Landa et al. 2007; Montes-Borrego et al. 2008; Voglmayr et al. 2014). Despite the importance of these diseases to poppy production, there are important knowledge gaps in disease epidemiology. Prior studies from Europe indicated that $P$. arborescens could be transmitted on contaminated poppy seed (Montes-Borrego et al. 2011), which following taxonomic reclassification is likely attributed to $P$. somniferi (Voglmayr et al. 2014). However, clarification of the relative role of poppy seed in the survival and transmission of both $P$. meconopsidis and $P$. somniferi is required. Furthermore, with the recent detection of systemic downy mildew symptoms in Australia, examination of the historic seed record may indicate more clearly when $P$. somniferi first appeared in Australian poppy crops. Seed transmission of downy mildew pathogens has also been demonstrated in other pathosystems (Clark and Spencer-Phillips 2004; Garibaldi et al. 2004; Inaba et al. 1983; Jang and Safeeulla 1990).

To test whether $P$. meconopsidis and/or $P$. somniferi can contaminate commercial poppy seed, we conducted histological examinations and seed washing assays of seed collected from commercial poppy crops from 1987 to 2016 to determine presence and abundance of Peronospora mycelia and oospores within these seed lots. To confirm pathogen presence in seed, we developed pathogen speciesspecific PCR and qPCR assays for the detection, differentiation, and quantification of $P$. meconopsidis and $P$. somniferi.

\section{Materials and Methods}

Seed collections. Forty-nine commercial opium poppy seed lots were supplied by Tasmanian Alkaloids Pty Ltd, Sun Pharmaceuticals (Australia) Pty Ltd, and TPI Enterprises Ltd. Seed lots were from crops harvested from 1987 to 2016. Seed samples from 2014 onward were obtained via collecting 10 to 20 subsamples (c. $5 \mathrm{~g}$ each) randomly selected from seed storage bins or from conveyor belts during postharvest processing. Historical seed lots (prior to 2014) consisted of single samples of up to $10 \mathrm{~g}$ of seed stored at ambient conditions. 
Development of species-specific PCR and qPCR assays for seed testing. Total genomic DNA from opium poppy leaf $(50 \mathrm{mg})$ or seeds (20 seeds per sample, c. $10 \mathrm{mg}$ ) was extracted using the PowerLyzer 24 homogenizer (QIAGEN, Chadstone, VIC, Australia) and the PowerPlant Pro DNA isolation kit with RNase treatment following the manufacturer's protocols (QIAGEN). Prior to PCR and qPCR, DNA yield was quantified using the Qubit 2.0 Flurometer (Life Technologies, Mulgrave, VIC, Australia), and DNA extracts were diluted to $5 \mathrm{ng}$ of total DNA/ $\mu$ l prior to use.

Potential species-specific primers for $P$. meconopsidis and $P$. somniferi were designed targeting the cytochrome oxidase subunit 1 (coxI) and subunit 2 (coxII) gene regions. Previously obtained sequences of coxI and coxII of the two species (GenBank accession numbers KX242325 and KX242326; Thangavel et al. 2017) were aligned using ClustalX in Geneious version 8.9.1 (Kearse et al. 2012). Primer sets from both regions were designed targeting SNPs within the aligned sequences associated with individual species. Primers targeting $P$. meconopsidis were coxI-PMF: TCATCAGC TATCGTTGAATCG; coxI-PMR: CCAAACAAATAAAGGTAATC TGTGA (coxI region) and coxII-PMF: CCGTGGTACATGGTG CTACTATC; coxII-PMR: ATTGTCCATAAAAAACACCCTCT (coxII region). Primers targeting $P$. somniferi's coxI region were coxI-PSF: ATCAGCCATTGTTGAATCAGGT; coxI-PSR: CAAA CAAATAAAGGTAATCTATGGAAG and coxII region were coxII-PSF: AAAAAATAAAATTCCAGCAACG; coxII-PSR: TGTCC GTAAAAAACACCTTCC. Primers had less than $85 \%$ similarity between the two species.

The specificity of each primer set for detection of the individual Peronospora spp. was tested by PCR. The following samples were included in each assay: 1) P. somniferi DNA extracted from conidiophores and conidia scraped from sporulating opium poppy leaves (positive control); 2) P. somniferi DNA extracted from a nonsporulating leaf with systemic symptoms; 3) $P$. somniferi DNA extracted from artificially contaminated seed (as described below); 4) P. meconopsidis DNA extracted from sporulating opium poppy leaves (positive control); 5) $P$. meconopsidis DNA from a nonsporulating leaf showing necrotic lesions; 6) $P$. meconopsidis DNA extracted from artificially contaminated seed (as described below); 7) DNA extracted from clean autoclaved seed (negative control); and 8) no template control. Presence of a PCR product of the appropriate size was used to confirm specificity of the PCR assay.

Annealing and denaturation temperatures for the various primer sets were optimized using a thermocycle of 35 cycles in a gradient PCR with the ranges of 48 to $65^{\circ} \mathrm{C}$ and 80 to $99^{\circ} \mathrm{C}$ for annealing and denaturation, respectively. Following selection of optimal primer sets for each pathogen (coxI-PSF and coxI-PSR for P. somniferi, coxII-PMF and coxII-PMR for P. meconopsidis), an optimized PCR thermocycle of $95^{\circ} \mathrm{C}$ for $15 \mathrm{~min}$, followed by 35 cycles of $95^{\circ} \mathrm{C}$ for $30 \mathrm{~s}, 60^{\circ} \mathrm{C}$ for $30 \mathrm{~s}$, and $72^{\circ} \mathrm{C}$ for $30 \mathrm{~s}$, and a final extension at $72^{\circ} \mathrm{C}$ for 10 min was used for all subsequent assays. All PCR amplifications were done with a $20-\mu$ l reaction mix containing $10 \mu \mathrm{l}$ of HotStartTaq Master Mix (QIAGEN), $0.75 \mu \mathrm{l}$ of $10 \mu \mathrm{M}$ forward and reverse primers, $1.5 \mu \mathrm{l}$ of $5 \mathrm{ng}$ of DNA template, $2 \mu \mathrm{l}$ of CoralLoad dye (QIAGEN), and $5 \mu \mathrm{l}$ of sterile water on a Mastercycler Gradient (Eppendorf, Hamburg, Germany). PCR products (6 $\mu \mathrm{l})$ were separated by electrophoresis in a $1 \%$ agarose gel in Tris-acetate-EDTA buffer (pH 8.0) containing 0.1\% SYBR Safe DNA Gel Stain (Life Technologies) and visualized under blue light.

Direct Sanger sequencing of selected PCR products was used to confirm species specificity. PCR products were purified with Isolate II PCR and Gel Kit (Bioline, Alexandria, NSW, Australia). DNA concentration was determined with the Nanodrop 8000 (Thermo Scientific, Australia). Products were then sequenced in both directions using the Genome Lab DTCS Quick Start Sequencing Kit (Beckman Coulter, Gladesville, NSW, Australia) with primers coxI-PSF and coxI-PSR ( $P$. somniferi) or coxII-PMF and coxII-PMR ( $P$. meconopsidis). Sequencing reactions were analyzed on a Beckman Coulter CEQ 8800 Genetic Analysis System. Obtained sequences were compared with previously published sequences by BLAST searching the GenBank nucleotide database (NCBI; https://blast.ncbi.nlm.nih.gov/Blast.cgi).
The same two optimized primer sets were then evaluated for quantitative PCR (qPCR) detection and enumeration of each species. Each 12.5- $\mu$ l reaction contained $6.25 \mu 1$ of QuantiTect SYBR Master Mix (QIAGEN), $0.75 \mu \mathrm{l}$ of $10 \mu \mathrm{M}$ forward and reverse primers, $1.5 \mu \mathrm{l}$ of $5 \mathrm{ng}$ of DNA template, and $2 \mu \mathrm{l}$ of sterile water. All amplifications were carried out in a Rotor Gene 6000 instrument (QIAGEN) with a thermocycle of $95^{\circ} \mathrm{C}$ for $15 \mathrm{~min}$, then 40 cycles of $95^{\circ} \mathrm{C}$ for $30 \mathrm{~s}$, $60^{\circ} \mathrm{C}$ for $60 \mathrm{~s}$, and $72^{\circ} \mathrm{C}$ for $60 \mathrm{~s}$, with three replicates per sample. The specificity of qPCR was determined using melt curve analysis (Guillemette et al. 2004). At the end of each qPCR cycle, the melting temperatures (at a rate of $1{ }^{\circ} \mathrm{C}$ every $5 \mathrm{~s}$ from 55 to $99^{\circ} \mathrm{C}$ ) of PCR products were examined for the presence of single dissociation peaks of increased fluorescence indicative of amplification of each species.

The quantity of $P$. meconopsidis and $P$. somniferi DNA in samples was calculated using the absolute quantification method (Bustin et al. 2009), with a standard curve determined from the amplification of 10-fold dilutions of a preamplified product of specific primers from $P$. meconopsidis and $P$. somniferi. From these regressions, an efficiency factor (Eff) was calculated using the internal software of the Rotor Gene 6000 (Corbett Research version 1.7). Samples that amplified with a $\mathrm{Cq}$ of greater than 30 cycles were considered negative based on occasional observations of false positive reactions from the nontemplate or healthy controls at, or close to, this threshold (e.g., Table 1).

Primer species specificity testing. To ensure species specificity of the optimized primer sets, an in silico analysis was conducted comparing sequence similarity with a range of Peronospora and related oomycete species within the primer regions. Each primer pair was subject to Primer-Blast (https://blast.ncbi.nlm.nih.gov/Blast. cgi) with the top 1,000 target sequences collated. In addition, Blastn of cox1 (P. somniferi) and cox2 (P. meconopsidis) sequences were done with the top 150 sequences added to the collection if not already present. Each sequence was then aligned using MAFFT in Geneious. Primer binding sites in each alignment were identified using the 'test primers' option in Geneious. Data from 1,072 (for coxI-PSF and coxI-PSR) and 1,032 (for coxII-PMF and coxII-PMR) isolates were compared with differences in nucleotide sequence and Tm recorded.

The two optimized primers (coxI-PSF and coxI-PSR for $P$. somniferi, coxII-PMF and coxII-PMR for $P$. meconopsidis) were then tested against nine nontarget downy mildew species, supplied by New South Wales Plant Pathology Herbarium, Orange, New South Wales (Supplementary Table S1). DNA was extracted from oospores and symptomatic leaf tissues $(\sim 50 \mathrm{mg})$ from the preserved herbarium specimens as previously described. PCR and qPCR testing were done with the optimized poppy downy mildew primer sets using the cycling conditions described previously. To check for false negatives, samples were also tested using the generic oomycete primer set: OomCoxI-Levup/OomCoxI-Levlo; 5'-TCAWCWMGATGGCTTTT TTCAAC-3'/5'-CYTCHGGRTGWCCRAAAAACCAAA-3' using the previously published reaction conditions (Robideau et al. 2011).

Seed detection limit by PCR and qPCR. Artificially contaminated seeds were generated by autoclaving $1 \mathrm{~g}$ of poppy seed (120 $\mathrm{kPa}$ for $15 \mathrm{~min}$ ) to kill existing seed contaminants. Conidia harvested from poppy leaves infected with either $P$. somniferi or $P$. meconopsidis were used to generate conidial suspensions $(2 \times$ $10^{6}$ conidia $/ \mathrm{ml}$ ) for each species. Autoclaved seeds were soaked in the conidial solutions for $24 \mathrm{~h}$ at 15 to $18^{\circ} \mathrm{C}$ and then air dried for $48 \mathrm{~h}$ in a laminar flow unit. Infested seed was then mixed with clean (autoclaved) seed at ratios (infested seed: clean seed) of 1:9,999, 1:999, $1: 499,1: 99,1: 49,1: 1$, and 0:1 to create seed lines of known incidences of infection for each species. DNA was extracted from each seed dilution sample and tested by PCR and qPCR to determine the seed detection threshold for each pathogen using the species-specific primers sets ( $P$. somniferi: coxI-PSF, coxI-PSR; $P$. meconopsidis: coxII-PMF, coxII-PMR). The DNA of each sample was extracted and tested by PCR and qPCR three times.

Microscopic observations of seed. Forty-five of the 49 seed lots (500 seeds per lot) were examined for the presence and abundance of fungi and oomycetes with the morphological features of Peronospora spp. Seeds were individually hand sectioned (10 sections per 
seed of $c .100 \mu \mathrm{m}$ thickness) using a sterile razor blade mounted on a glass slide and stained with lactophenol cotton blue/trypan blue (Sigma-Aldrich, Castle Hill, NSW, Australia) for 5 min (Kunjeti et al. 2016). Sections were then examined microscopically at $200 \times$ magnification (Leica DMLB, Type LB 30T compound microscope; Leica Microsystems Pty Ltd, Australia) for the presence of Peronospora spp. mycelia and oospores.

Seed washing and oospore viability. Seed from 20 representative seed lots, including crops harvested from 1987 to 2016, were evaluated for the presence of Peronospora spp. oospores using a seedwash and viability stain protocol adapted from previous work (Inaba et al. 1983; Kunjeti et al. 2016; Testen et al. 2014). Each seed lot was

\section{$\begin{array}{lllllllll}M & 1 & 2 & 3 & 4 & 5 & 6 & 7 & 8\end{array}$}

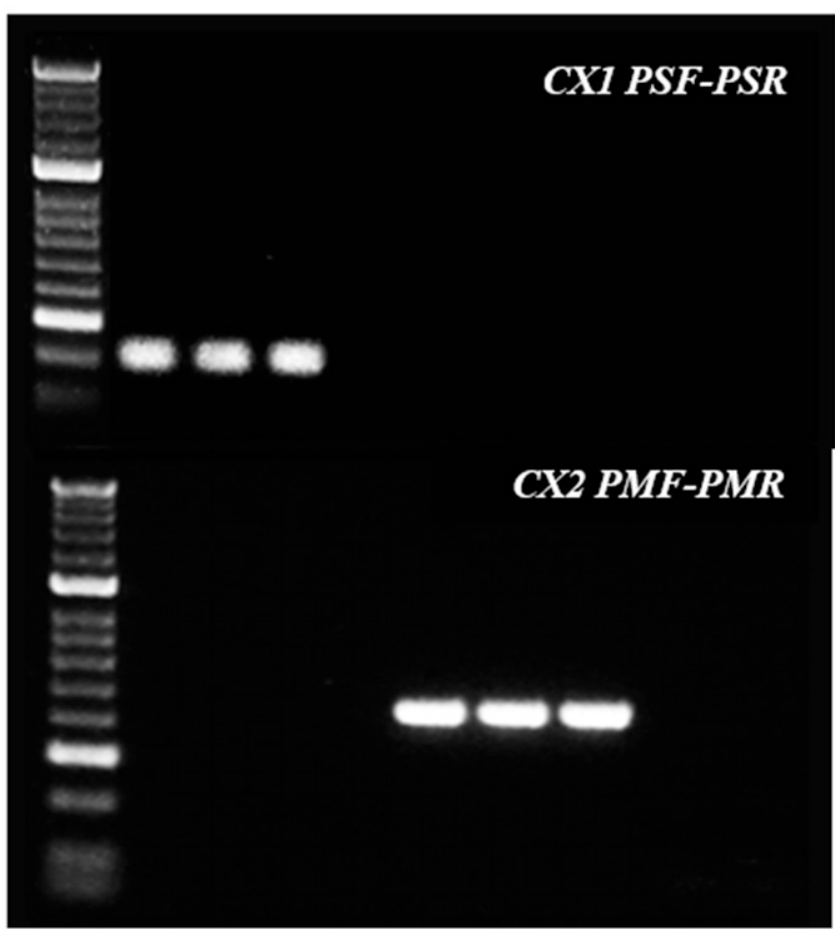

Fig. 1. Confirmation of species-specific amplification of Peronospora somniferi and P. meconopsidis with primers coxI-PSF, coxI-PSR and coxll-PMF, coxII-PMR, respectively. M, DNA 100-bp ladder marker; lane 1, P. somniferi conidia and conidiophores from infected opium poppy leaves (positive control); lane 2, $P$. somniferi systemically infected poppy leaves; lane $3, P$. somniferi artificially contaminated seed; lane 4, P. meconopsidis conidia and conidiophores from infected opium poppy leaves (positive control); lane 5, P. meconopsidis-infected poppy leaves; lane $6, P$. meconopsidis artificially contaminated seed; lane 7 , clean seed of Papaver somniferum; lane 8, non-DNA control. counted and weighed four times, and the number of seeds per gram in the lots varied from 1,664 to 2,435 seeds. Six samples of $0.3 \mathrm{~g}$ seed were assessed for each seed lot. Each sample was stirred in $1.8 \mathrm{ml}$ of deionized water in a $25-\mathrm{ml}$ beaker for $30 \mathrm{~min}$ using a magnetic stirrer. The seed wash suspension was decanted into a 2-ml microcentrifuge tube and centrifuged at 4,000 $\times g$ for $5 \mathrm{~min}$. The supernatant was decanted, and the resulting pellet resuspended in $30 \mu$ l of deionized water and vortexed briefly to mix. Trypan blue $(30 \mu \mathrm{l}$ of $0.4 \% \mathrm{wt} / \mathrm{vol}$ solution; Sigma-Aldrich) was added, mixed briefly, and allowed to stand for $1 \mathrm{~min}$. Six $10-\mu l$ aliquots of each suspension were examined at 100 to $200 \times$ magnification with the number of nonviable (blue stained) and putatively viable (unstained) oospores recorded.

Incidence of $P$. somniferi and $P$. meconopsidis in seed lots estimated by PCR and qPCR. The same 20 seed lots as used for the seed washing assay were tested by PCR and qPCR for the presence of the two poppy downy mildew pathogens. For each seed lot, DNA was extracted and quantified from 20 replicate subsamples of 20 seeds (400 seeds total) as described previously. Poppy seed artificially contaminated with $P$. somniferi and $P$. meconopsidis were included as positive controls in all the assays. All PCR and qPCR reactions were carried out as mentioned previously. Following both PCR and qPCR assays, the percent contamination within the grouped seed samples was estimated using the binomial theorem (Gibbs and Gower 1960). In qPCR assays, the mean concentration of pathogen DNA per seed sample was also determined.

Correlation between histological and molecular estimates of seed contamination. The relationship between the individual estimates of seed contamination incidence was assessed statistically using the Spearman's rank correlation index. Pairwise correlations were conducted comparing contamination rate estimates from the number of oospores estimated by seed washing, the number of positive samples determined by PCR, and the quantity of pathogen DNA determined by qPCR testing. All statistical analyses were performed in the R statistical language environment version 3.1 (R Core Team 2015).

Confirmation of disease transmission via seed inoculum. Two experiments were conducted to confirm transmissibility of the two Peronospora spp. from infested seed to infected seedlings. Seed lot SL22 was used for both experiments with trials established in July and September 2016. For both experiments, seed raising trays $(60 \times$ $40 \times 12 \mathrm{~cm}$ ) were filled with a potting mix containing sand, peat, and composted pine bark (10:10:80, $\mathrm{pH}$ 6.0) premixed with Osmocote 16-3.5-10 NPK resin coated fertilizer (Scotts Australia Pty Ltd). In each tray, $0.5 \mathrm{~g}$ seeds (c. 1,000 seeds) were sown and covered with a $5-\mathrm{cm}$ layer of potting mix. In total, 100 trays were sown for each experiment. Experiments were conducted in a glasshouse with temperatures maintained at $18-20^{\circ} \mathrm{C}$ with relative humidity of $70-75 \%$. Hand watering occurred twice daily avoiding watering directly onto leaves. Visual disease assessments were conducted weekly after seedling emergence. PCR testing of seedlings for the presence of each pathogen was done 8 weeks after sowing. Aboveground leaf and stem tissues free of remnant seed and crop debris were harvested.

Table 1. PCR and qPCR detection limits for Peronospora somniferi and P. meconopsidis in artificially infested seed mixes

\begin{tabular}{|c|c|c|c|c|c|c|}
\hline \multirow[b]{3}{*}{ Seed mixture ${ }^{a}$} & \multirow{2}{*}{\multicolumn{2}{|c|}{$\mathbf{P C R}^{\mathbf{b}}$}} & \multicolumn{4}{|c|}{ qPCR } \\
\hline & & & \multicolumn{2}{|c|}{ P. meconopsidis } & \multicolumn{2}{|c|}{ P. somniferi } \\
\hline & P. meconopsidis & P. somniferi & Mean $\mathrm{Cq}^{\mathrm{c}}$ & DNA concentration & Mean $\mathrm{Cq}^{\mathrm{c}}$ & DNA concentration \\
\hline $0: 1$ & $-\ldots$ & $-\ldots$ & $30.42 \pm 0.03$ & $0.00 \pm 0.00$ & $38.45 \pm 1.88$ & $0.00 \pm 0.00$ \\
\hline $1: 1$ & +++ & +++ & $4.63 \pm 0.05$ & $5916.29 \pm 0.18$ & $3.71 \pm 0.45$ & $1088.61 \pm 334.25$ \\
\hline $1: 49$ & +++ & +++ & $4.64 \pm 0.01$ & $313.45 \pm 8.74$ & $4.85 \pm 0.50$ & $623.36 \pm 4.65$ \\
\hline 1:99 & +++ & +++ & $14.49 \pm 0.02$ & $9.36 \pm 0.05$ & $15.70 \pm 0.94$ & $14.84 \pm 0.01$ \\
\hline 1:499 & \pm \pm \pm & \pm \pm- & $19.57 \pm 0.02$ & $6.89 \pm 0.06$ & $17.35 \pm 0.85$ & $3.94 \pm 0.01$ \\
\hline 1:999 & \pm- & \pm - - & $20.96 \pm 0.007$ & $4.65 \pm 0.01$ & $17.81 \pm 0.63$ & $2.76 \pm 0.03$ \\
\hline 1:9999 & \pm-- & \pm- & $21.44 \pm 0.01$ & $0.07 \pm 0.03$ & $27.8 \pm 0.82$ & $0.14 \pm 0.073$ \\
\hline
\end{tabular}

${ }^{\text {a }}$ Ratio of artificially contaminated seeds to clean (autoclaved) seed.

${ }^{\mathrm{b}}$ Primers coxII-PMF-PMR for $P$. meconopsidis and coxI-PSF-PSR for $P$. somniferi were used for all PCR and qPCR assays. Results were obtained from three independent operators with same seed mixture ratio: $+=$ positive amplification, $\pm=$ positive weak amplification, and $-=$ no amplification.

${ }^{\mathrm{c}} \mathrm{Cq}$ values and estimated DNA concentration were obtained from the mean three runs of qPCR with same seed mixture ratio ( \pm standard error of mean). DNA concentrations are expressed in $\mathrm{pg} / \mathrm{g}$ of seed and were calculated using the standard curve developed in this study. 
Ten (experiment 1) or 20 (experiment 2) seedlings were handpicked from each of the 10 trays and combined for DNA extraction and testing (giving a total of 1,000 and 2,000 plants tested in each experiment). Grouped samples were ground using a mortar and pestle, and $200 \mu \mathrm{l}$ of homogenized plant tissue was taken for DNA extraction as previously described. PCR testing for the presence of $P$. somniferi and $P$. meconopsidis of each grouped sample was conducted as previously described. Incidence of seedling infection was estimated using the binomial theorem (Gibbs and Gower 1960) based on 10 grouped samples per experiment.

\section{Results}

Development of species-specific PCR and qPCR assays for seed testing. The four primer sets proved to be species-specific without any cross amplification of the alternate poppy downy mildew species. From these four, two primer sets were selected for subsequent PCR and qPCR assays: $P$. somniferi (coxI-PSF, coxI-PSR) and $P$. meconopsidis (coxII-PMF, coxII-PMR) reproducibly amplified DNA fragments of $217 \mathrm{bp}$ and $441 \mathrm{bp}$, respectively (Fig. 1). Sequencing of the PCR products confirmed that the identities of the amplicons were consistent with the gene region of their respective targets. PCR specificity was consistent in all samples extracted from $P$. somniferi and $P$. meconopsidis infected leaves, seed, and from conidial spore suspensions (Fig. 1). Furthermore, no amplification was observed when tested against nine other downy mildew species. The in silico analysis compared the two optimized primer sets (coxI-PSF, coxI-PSR; and coxII-PMF, coxII-PMR) with 1,072 isolates from GenBank (Supplementary Tables S2 and S3). For all primers, a minimum of one and a maximum of seven mismatched nucleotides were found. The melting temperatures of $P$. somniferi and $P$. meconopsidis primers were $60.4^{\circ} \mathrm{C}$ (coxI-PSF), $56.9^{\circ} \mathrm{C}$ (coxI-PSR), $63.5^{\circ} \mathrm{C}$ (coxII$\mathrm{PMF}$ ), and $58.2^{\circ} \mathrm{C}$ (coxII-PMR), and these were distinctly greater than other species listed.

In $\mathrm{qPCR}$, the species-specific primers coxI-PSF, coxI-PSR and coxII-PMF, coxII-PMR also amplified their specific species targets without any cross amplification. The $\mathrm{qPCR}$ products showed distinct melt curves with peaks at 76.2 and $77.4^{\circ} \mathrm{C}$ for $P$. somniferi and $P$. meconopsidis, respectively. The reproducibility of the qPCR assay was tested by calculating the $\mathrm{Cq}$ values and the standard curve efficiency from three consecutive runs on three different days (Fig. 2).

Seed detection limits were assessed on seeds that had been artificially inoculated with conidial spore suspensions of either $P$. somniferi or P. meconopsidis. In the PCR assays, the target Peronospora spp. was consistently detected from artificially contaminated seed diluted 1:1 to 1:99 with clean seed (Table 1). Weak positive bands were commonly (1:499) or occasionally (1:999 to 1:9,999) detected at greater dilutions. For qPCR, successful detection of pathogen was achieved at all dilutions up to 1:9,999 (Table 1). Associations were found between the $\mathrm{Cq}$ value or DNA level calculated, and the increasing dilution of infested seed within the seed mixture (Table 1).

Microscopic observations of seed. The presence of Peronospora spp. in the seed samples was suggested based on the relative morphological features; including shriveled, fragmented nonseptate hyphae, branching hyphae, conidia and oospores on the seed coat spermoderm, endosperm, and embryo regions (Clark and Spencer-Phillips 2004). Peronospora spp.-like mycelia were typically observed on the outer surface of the seed penetrating the seed coat spermoderm tissues either inter- or intracellularly. Hyphae were only rarely found within the seed endosperm or embryo tissues. Accurate determination of the position of oospores during dissection was problematic; however, most appeared to be found external to the seed coat, with rare observations suggestive of oospore presence inside the seed coat. The 45 seed lots examined by microscopy all contained mycelium or oospores consistent with Peronospora spp. (Table 2). However, the estimated level of seed contamination varied between seed lots. The frequency of Peronospora spp.-like mycelia observed on the outside of the seed coat varied from 2.0 to $66.6 \%$ and within the seed coat from 0.0 to $7.8 \%$. Seed lots harvested in 2014 (SL21 and SL22) showed the highest incidence on the outer surface of the seed coat, with 66.6 and $57.0 \%$, respectively. The presence of oospores was highest in seed lot SL32 at 1.8\% (Table 2).

Seed washing and oospore viability. Oospores were observed in seed washes from 19 of the 20 seed lots tested (Table 3 ). The number of oospores observed in each 1.8-g sample varied from 0 (SL41) to 112 (SL10). Staining clearly differentiated putatively viable (nonstained) from nonviable (stained) oospores. Putatively viable

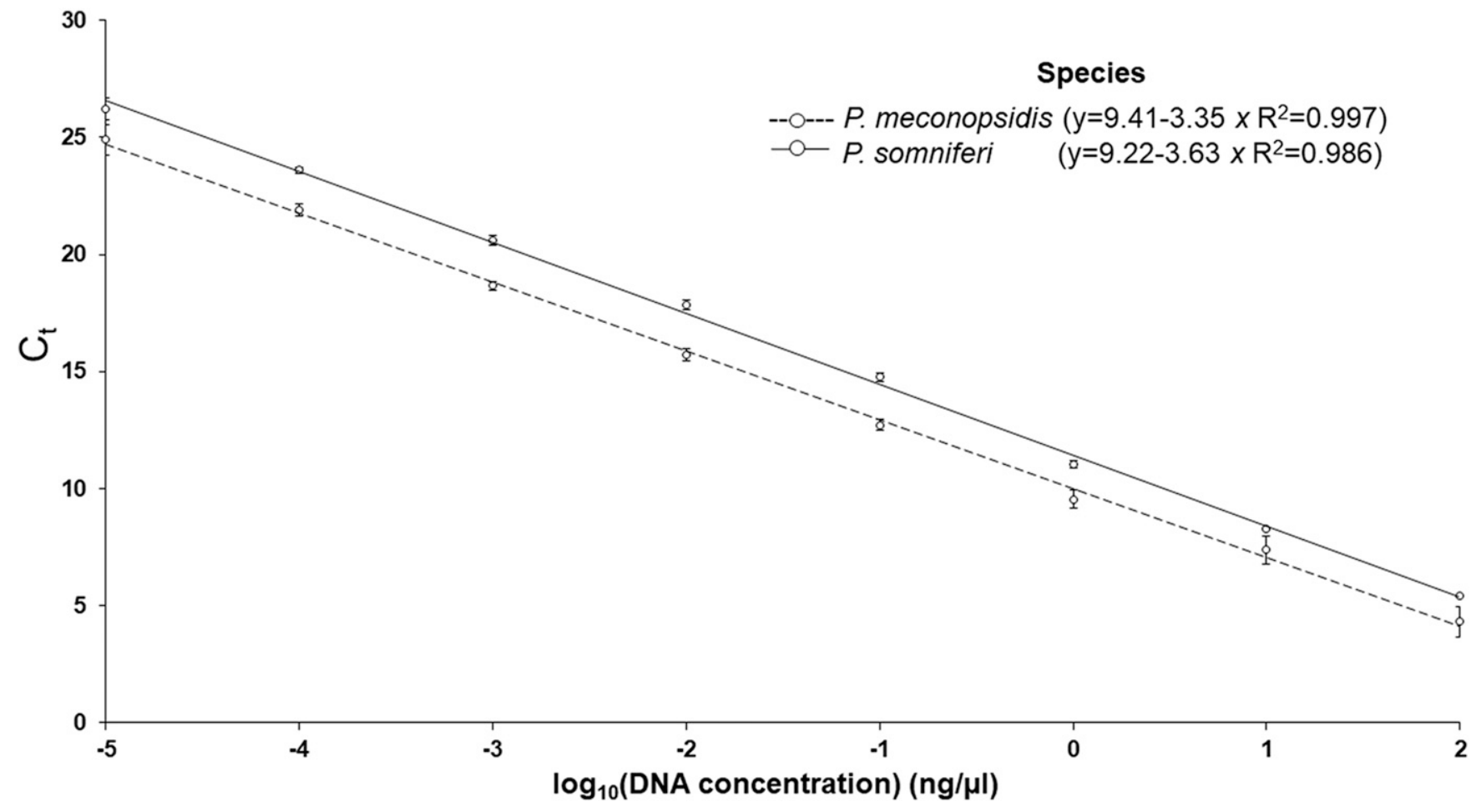

Fig. 2. Standard linear regression curves for qPCR amplification of Peronospora meconopsidis and $P$. somniferi, respectively. qPCR reactions were conducted over an eightfold serial dilution of target DNA from $100 \mathrm{ng} / \mu \mathrm{l}(\log 10=2)$ to $0.01 \mathrm{pg} / \mu \mathrm{l}(\log 10=-5)$. Error bars represent the standard deviation of $\mathrm{Ct}$ values among three runs, with four technical replicates per run. Equations of the linear regression, and associated $R^{2}$ estimates, for each primer pair are indicated in the figure. 
oospores were found in 17 seed lots, including samples collected from seed lots harvested as early as 1987 (Table 3). No putatively viable oospores were found in seed lots SL14 and SL 37 (Table 3).

Incidence of $\boldsymbol{P}$. somniferi and $\boldsymbol{P}$. meconopsidis in seed lots estimated by PCR and qPCR. In conventional PCR testing, 15 of the 20 seed lots (each 20 samples of 20 seeds) showed positive detections of $P$. meconopsidis with the greatest number of detections found in SL10, harvested in 2014 (11/20 grouped samples; estimated incidence $=3.91 \%)$, and in SL46, harvested in 2015 (14/20; estimated incidence $=5.84 \%$ ). Detection success was notably lower in seed lots collected from 1987 to 2007 , with a maximum of $3 / 20(0.81 \%)$ positives recorded in any individual seed lot from this period. $P$. meconopsidis was not detected in one seed lot from 2012 and in four seed lots from 2015 (Table 3). Quantitative PCR proved more sensitive with positive detections from 18 of the 20 seed lots, and the number of positive samples detected either remained the same or increased from that found with conventional PCR (Table 3). The highest recorded number of detections was 17/20 (9.05\%) from SL47 collected in 2015. Samples collected prior to 2012 showed detection levels from $2 / 20(0.53 \%)$ to $8 / 20(2.52 \%)$.

For $P$. somniferi, no positive detections were observed from the five seed lots (1987-2007) collected prior to 2012. Positive detections were observed in 13 of the remaining 15 seed lots by conventional PCR and in all seed lots from 2012 onward by qPCR (Table 3). The two seed lots from 2015 from which P. somniferi was not detected by conventional PCR (SL43 and SL44) showed low levels of detection ( $1 / 20$ and $2 / 20$ ) by qPCR (Table 3 ). In conventional PCR assays, detection levels in seed lots from 2012 to 2016 varied from $0 / 20$ to $18 / 20$ (10.87\%). In qPCR, detection levels ranged from $1 / 20(0.25 \%)$ to $20 / 20$.

The DNA concentrations of $P$. meconopsidis and $P$. somniferi present in the seed lots reflected the observed detection levels. P. meconopsidis DNA levels varied from below detection limits (SL43 and SL44) to a maximum of $35.17 \mathrm{pg} / \mathrm{g}$ seed (SL22; 2014). Similarly, $P$. somniferi DNA levels varied from below detection limits (all seed lots collected prior to 2012) to a maximum of $33.04 \mathrm{pg} / \mathrm{g}$ seed (SL22; 2014).

Correlation between histological and molecular estimates of contamination. There was a significant positive correlation between conventional PCR and qPCR results $(r=0.81 ; P<0.01)$, but no correlation was observed between the spore wash assay that enumerates oospores and either PCR assay (Table 4).

Confirmation of disease transmission via seed inoculum. Seedlings up to 8 weeks after sowing did not show any symptoms of infection in either experiment. PCR testing of harvested stem and leaf tissues resulted in positive detections in experiment 1 of $P$. somniferi ( 1 of 10 grouped samples giving an estimated incidence of $0.1 \%$ ). In experiment 2 , both $P$. somniferi ( 2 of 10 grouped samples) and $P$. meconopsidis (1 of 10 grouped samples) were detected, giving an estimated incidence of 0.1 and $0.05 \%$ for the two pathogens, respectively.

\section{Discussion}

The discovery of two Peronospora spp. causing distinct downy mildew symptoms in opium poppy in Australia (Thangavel et al. 2017) has necessitated a re-evaluation of the epidemiology of these diseases including the role of seed as a means for pathogen survival and spread. The work presented here has confirmed the presence of both $P$. meconopsidis and $P$. somniferi contamination in poppy seed. Previously, P. arborescens was reported as seed-borne in Spanish poppy seed (Landa et al. 2007; Montes-Borrego et al. 2008). Following the reclassification of Peronospora spp. infecting Papaver hosts, $P$. arborescens was considered to only infect the weed poppy species $P$. rhoeas (Voglmayr et al. 2014). It is presumed that these instances of $P$. arborescens contamination of opium poppy in Spain can be attributed to $P$. somniferi, but this has yet to be confirmed. To the best of our knowledge, $P$. meconopsidis has not previously been reported associated with opium poppy seed.

In this study, we found Peronospora spp. in most of the opium poppy seed stocks tested from 1987 to 2016 harvests either in the form of oospores or mycelium. Mycelium was primarily found on inter- and intracellular tissues of the seed surface coat spermoderm layer and rarely in inner tissues of endosperm and embryo. While it was not possible to definitively determine the position of oospores in seed by histological examination, most appeared located external to the seed coat. This suggests that physical or chemical seed surface disinfestation treatments may be effective at reducing seed-borne inoculum (du Toit and Hernandez-Perez 2005; Nega et al. 2003; White et al. 1984). Studies in other downy mildew pathosystems, including soybean, sunflower, and the Cucurbitaceae family (Cohen et al.

Table 2. Detection of Peronospora spp. mycelia and oospores in or on opium poppy seed

\begin{tabular}{|c|c|c|c|c|}
\hline \multirow[b]{2}{*}{ Harvest year } & \multirow[b]{2}{*}{ Seed lot } & \multicolumn{3}{|c|}{$\begin{array}{l}\text { Incidence }(\%) \text { of observed } \\
\text { Peronospora propagules }\end{array}$} \\
\hline & & $\begin{array}{l}\text { Mycelium } \\
\text { outside the } \\
\text { seed coat }^{\mathrm{a}}\end{array}$ & $\begin{array}{l}\text { Mycelium } \\
\text { inside the } \\
\text { seed coat }\end{array}$ & Oospores $^{b}$ \\
\hline 1987 & SL36 & 0 & 0 & 0 \\
\hline 1988 & SL37 & 0 & 0 & 0 \\
\hline 1999 & SL38 & 0 & 0 & 0 \\
\hline 2005 & SL39 & 0 & 0 & 0 \\
\hline 2007 & SL40 & 0 & 0 & 0 \\
\hline 2011 & SL15 & 10.0 & 1.0 & 0 \\
\hline 2012 & SL01 & 2.0 & 0 & 0 \\
\hline 2012 & SL14 & 8.4 & 1.0 & 0 \\
\hline 2012 & SL16 & 21.4 & 0.8 & 0.6 \\
\hline 2012 & SL17 & 18.4 & 7.0 & 0 \\
\hline 2012 & SL19 & 3.2 & 1.0 & 0.2 \\
\hline 2012 & SL20 & 6.2 & 1.0 & 0 \\
\hline 2013 & SL02 & 8.2 & 1.0 & 0 \\
\hline 2013 & SL11 & 32.6 & 1.0 & 0 \\
\hline 2014 & SL03 & 11.4 & 0 & 0 \\
\hline 2014 & SL04 & 38.8 & 7.8 & 0 \\
\hline 2014 & SL05 & 3.8 & 1.8 & 0 \\
\hline 2014 & SL06 & 10.4 & 0.2 & 0 \\
\hline 2014 & SL07 & 15.6 & 1.6 & 0 \\
\hline 2014 & SL08 & 5.2 & 1.0 & 0 \\
\hline 2014 & SL09 & 8.4 & 2.0 & 0 \\
\hline 2014 & SL10 & 19.6 & 0.8 & 1 \\
\hline 2014 & SL12 & 19.0 & 1.8 & 0 \\
\hline 2014 & SL13 & 22.4 & 0 & 0 \\
\hline 2014 & SL18 & 37.0 & 0 & 0 \\
\hline 2014 & SL21 & 66.6 & 3.4 & 0.2 \\
\hline 2014 & SL22 & 57.0 & 4.2 & 0.2 \\
\hline 2014 & SL23 & 4.4 & 1.4 & 0 \\
\hline 2014 & SL24 & 7.4 & 1.8 & 0.2 \\
\hline 2014 & SL25 & 2.8 & 0.4 & 0 \\
\hline 2014 & SL26 & 1.6 & 0.6 & 0 \\
\hline 2015 & SL27 & 10.4 & 2.8 & 0.6 \\
\hline 2015 & SL28 & 17.0 & 4.2 & 0.6 \\
\hline 2015 & SL29 & 9.4 & 4.8 & 0.2 \\
\hline 2015 & SL30 & 9.6 & 1.4 & 1.6 \\
\hline 2015 & SL31 & 6.6 & 2.4 & 0.6 \\
\hline 2015 & SL32 & 3.0 & 0.4 & 1.8 \\
\hline 2015 & SL33 & 2.8 & 0.4 & 0 \\
\hline 2015 & SL34 & 5.2 & 1.8 & 0 \\
\hline 2015 & SL35 & 2.4 & 0.2 & 0 \\
\hline 2016 & SL41 & 17.4 & 0.4 & 0 \\
\hline 2016 & SL42 & 5.8 & 0.6 & 0 \\
\hline 2016 & SL43 & 2.6 & 0.2 & 0.2 \\
\hline 2016 & SL44 & 0.2 & 0 & 0 \\
\hline 2016 & SL45 & 1.0 & 0 & 0 \\
\hline
\end{tabular}

${ }^{a}$ Mycelium outside the seed coat were observed on the outer surface of the seed penetrating the seed coat spermoderm tissues either inter- or intracellularly. Mycelia inside the seed coat were found within the seed endosperm or embryo tissues.

${ }^{\mathrm{b}}$ Seed dissection led to dislodgement of oospores, and thus it was not possible to definitively assess whether observed oospores were internal or external to seed coat. 
2014; Döken 1989) have also shown that Peronospora spp. can survive in or on seed as mycelium and oospores and can act as inoculum for subsequent crops (Adenle and Cardwell 2000; Inaba et al. 1983; Yao et al. 1990). It is of interest that putatively viable oospores were detected in seed lots harvested as far back as 1987 . This extended period of oospore viability, $c .19$ years at the time of testing, is not without precedent within the genus; $P$. destructor oospores can germinate 25 years after their formation (McKay 1957).

We found P. meconopsidis in almost all seed lots tested from 1987 to 2016. P. meconopsidis was first reported in Tasmanian poppy in 1996 (Cotterill and Pascoe 1998). This suggests that P. meconopsidis was present in Australian crops for a considerable length of time prior to its detection. In contrast, $P$. somniferi has only recently been reported in Australia (Thangavel et al. 2017). While noting that we did not have access to seed lots from the 2008 to 2011 harvests, $P$. somniferi was only found in seed lots harvested from 2012 or later, which supports the hypothesis that this species is a relatively recent introduction to Australian crops. The first reports of systemic downy mildew infections of commercial crops occurred during the 2013-14 growing season (Thangavel et al. 2017). That $P$. somniferi was detected in seed harvested in 2012 suggests that $P$. somniferi was present within Australian crops prior, but at incidences low enough to avoid detection in commercial crops until 2013. P. somniferi is found in European poppy crops (Landa et al. 2007; Montes-Borrego et al. 2011). The exact timing and method of how P. somniferi arrived in Australia is not known.

Microscopic and PCR-based detection methods of downy mildew in poppy seed provide complementary but distinct information on the presence, identity, and form of pathogens in seed. PCR detection can be a reliable and sensitive method to detect pathogen presence and identify pathogen species, but does not distinguish between putatively viable and nonviable pathogen structures. Microscopic examination is often time-consuming and laborious, and it is not always possible to differentiate between the Peronospora spp. (Walcott 2003). However, microscopic observations facilitate identification of pathogen structures, such as conidia and oospores, as well as determination of spore viability, thus providing additional information of potential sources of inoculum. Further studies are required to examine the relative importance of oospores, mycelia, and conidia in seed for transmission to seedlings (Inaba et al. 1983; Kunjeti et al. 2016; McGee 1995).

Until now, species-specific assays for downy mildew pathogens of poppy were based on primers targeting the ITS gene region (MontesBorrego et al. 2009; Scott et al. 2004), which does not always accurately resolve species boundaries within the Peronospora (Voglmayr et al. 2014). In this study, we developed PCR and qPCR assays targeting the coxI and coxII gene regions for the detection and quantification of both $P$. somniferi and $P$. meconopsidis in poppy seed. A detailed in silico analysis of the species-specific primer pairs demonstrated these sequences were distinct from other Peronospora and related species available in GenBank, and subsequent absence of amplicons following testing against nine distinct downy mildew species commonly found in Australia demonstrate species specificity of the tests. Sequencing of selected amplicons from the seed test consistently revealed sequences that corresponded to the target species and confirmed seed test specificity. Furthermore, as poppy seed forms in enclosed capsules, it would be protected from environmental contamination by other oomycetes. Thus, we have demonstrable confidence in the ability of the PCR and qPCR tests to specifically detect and enumerate the individual poppy downy mildew pathogens. As part of the quantification process, we developed a standardized sampling method for commercial poppy seed stocks to determine the incidence and severity of Peronospora spp. To ensure

Table 4. Correlation between pathogen estimates by PCR, qPCR, and seed washing

\begin{tabular}{llc}
\hline & \multicolumn{1}{c}{ qPCR } \\
(pg DNA/g seed) & $\begin{array}{c}\text { PCR } \\
\text { (no. of positives) }\end{array}$ \\
\hline $\begin{array}{l}\text { PCR (no. of. positives) } \\
\begin{array}{l}\text { Oospores observed by } \\
\text { seed washing }\end{array}\end{array}$ & $0.81(P=0.004)$ & - \\
\hline
\end{tabular}

Table 3. Estimation of Peronospora meconopsidis and P. somniferi abundance level in seed lots using PCR, qPCR, and the oospore seed wash assay

\begin{tabular}{|c|c|c|c|c|c|c|c|c|c|}
\hline \multirow[b]{3}{*}{ Harvest year } & \multirow[b]{3}{*}{ Seed lot } & \multirow{2}{*}{\multicolumn{2}{|c|}{ Oospores $^{\mathbf{a}}$}} & \multicolumn{3}{|c|}{ P. meconopsidis } & \multicolumn{3}{|c|}{ P. somniferi } \\
\hline & & & & \multirow{2}{*}{$\begin{array}{c}\text { PCR } \\
\text { detections }^{b}\end{array}$} & \multirow{2}{*}{$\begin{array}{c}\text { qPCR } \\
\text { detections }\end{array}$} & \multirow{2}{*}{$\begin{array}{l}\text { DNA pg/g } \\
\text { of seed }^{\mathrm{c}}\end{array}$} & \multirow{2}{*}{$\begin{array}{c}\text { PCR } \\
\text { detections }^{b}\end{array}$} & \multirow{2}{*}{$\begin{array}{c}\text { qPCR } \\
\text { detections }\end{array}$} & \multirow{2}{*}{$\begin{array}{c}\text { DNA pg/g } \\
\text { of seed }^{\mathrm{c}}\end{array}$} \\
\hline & & Viable & Nonviable & & & & & & \\
\hline 1987 & SL36 & 2 & 15 & $1(0.26)$ & $2(0.53)$ & $0.02(0.00-1.36)$ & $0(0.00)$ & $0(0.00)$ & $0.00(0.00-0.00)$ \\
\hline 1988 & SL37 & 0 & 12 & $1(0.26)$ & $5(1.43)$ & $0.12(0.00-3.69)$ & $0(0.00)$ & $0(0.00)$ & $0.00(0.00-0.00)$ \\
\hline 1999 & SL38 & 1 & 11 & $2(0.53)$ & $2(0.53)$ & $2.96(0.00-10.11)$ & $0(0.00)$ & $0(0.00)$ & $0.00(0.00-0.00)$ \\
\hline 2005 & SL39 & 3 & 13 & $1(0.26)$ & $1(0.26)$ & $0.04(0.00-1.21)$ & $0(0.00)$ & $0(0.00)$ & $0.00(0.00-0.00)$ \\
\hline 2007 & SL40 & 4 & 4 & $3(0.81)$ & $8(2.52)$ & $7.31(0.00-19.78)$ & $0(0.00)$ & $0(0.00)$ & $0.00(0.00-0.00)$ \\
\hline 2012 & SL14 & 0 & 21 & $0(0.00)$ & $5(1.43)$ & $8.26(0.00-17.16)$ & $5(1.43)$ & $14(5.82)$ & $17.36(0.00-95.36)$ \\
\hline 2014 & SL03 & 3 & 23 & $8(2.52)$ & $12(4.48)$ & $8.91(0.00-29.44)$ & $7(2.13)$ & $8(2.52)$ & $16.25(0.00-23.78)$ \\
\hline 2014 & SL06 & 4 & 32 & $8(2.52)$ & $8(2.52)$ & $21.74(0.00-37.71)$ & $8(2.52)$ & $12(4.47)$ & $20.21(0.00-37.10)$ \\
\hline 2014 & SL07 & 6 & 56 & $5(1.43)$ & $4(1.11)$ & $8.23(0.00-19.36)$ & $1(0.26)$ & $1(0.25)$ & $1.36(0.00-21.01)$ \\
\hline 2014 & SL10 & 9 & 103 & $11(3.91)$ & $13(5.11)$ & $12.36(0.00-17.98)$ & $10(3.41)$ & $18(10.87)$ & $7.96(0.00-47.36)$ \\
\hline 2014 & SL22 & 2 & 47 & $7(2.13)$ & $9(2.94)$ & $35.17(0.00-220.73)$ & $8(2.52)$ & $10(3.40)$ & $33.04(0.00-220.53)$ \\
\hline 2016 & SL41 & 0 & 0 & $1(0.26)$ & $6(1.77)$ & $0.02(0.00-0.41)$ & $3(0.81)$ & $14(5.84)$ & $0.60(0.00-7.59)$ \\
\hline 2016 & SL42 & 2 & 1 & $0(0.00)$ & $3(0.81)$ & $2.08(0.00-30.46)$ & $2(0.53)$ & $8(2.52)$ & $0.04(0.00-1.55)$ \\
\hline 2016 & SL43 & 4 & 3 & $0(0.00)$ & $0(0.00)$ & $0.00(0.00-0.00)$ & $0(0.00)$ & $1(0.26)$ & $0.00(0.00-0.03)$ \\
\hline 2016 & SL44 & 2 & 5 & $0(0.00)$ & $0(0.00)$ & $0.00(0.00-0.00)$ & $0(0.00)$ & $2(0.52)$ & $0.00(0.00-0.16)$ \\
\hline 2016 & SL45 & 7 & 17 & $6(1.77)$ & $10(3.41)$ & $7.76(0.00-56.73)$ & $15(6.70)$ & $20(100)$ & $6.15(0.00-70.52)$ \\
\hline 2016 & SL46 & 3 & 20 & $14(5.84)$ & $15(6.70)$ & $5.70(0.00-31.23)$ & $18(10.87)$ & $20(100)$ & $4.35(0.00-56.85)$ \\
\hline 2016 & SL47 & 1 & 9 & $9(2.94)$ & $17(9.05)$ & $11.51(0.00-43.68)$ & $17(9.05)$ & $20(100)$ & $4.37(0.00-82.71)$ \\
\hline 2016 & SL48 & 1 & 17 & $4(1.11)$ & $4(1.11)$ & $1.23(0.00-14.36)$ & $7(2.13)$ & $7(2.13)$ & $0.28(0.00-4.06)$ \\
\hline 2016 & SL49 & 6 & 22 & $0(0.00)$ & $2(0.53)$ & $0.00(0.00-0.51)$ & $8(2.52)$ & $12(4.47)$ & $3.42(0.00-36.93)$ \\
\hline
\end{tabular}

a Total number of oospores observed from washing $1.8 \mathrm{~g}$ of seed with $10.8 \mathrm{ml}$ of water and staining with $0.4 \%$ tryphan blue. Viable oospores remained unstained, nonviable oospores were stained blue.

${ }^{b}$ Results were obtained from 20 subsamples of 20 seeds from individual seed lots by PCR and qPCR, respectively. In PCR, weak positive amplifications were also considered as a positive detection, and in qPCR, samples that amplified at greater than $30 \mathrm{Cq}$ were not considered positive detections. Values in parentheses indicate the estimated percent incidence of seed contamination based on the testing procedure of Gibbs and Gower (1960) except for seed lots that tested positive for all grouped samples for which such analysis is not possible. The results of pathogen incidence (\%) were obtained from positive detections of 20 subsamples of individual seed lots.

${ }^{c}$ Estimated pathogen DNA (pg/g of seed) based on qPCR standard curve quantification. Range of estimates across 20 subsamples presented with parentheses. 
the homogeneity of samples, random sampling was used. To increase the sensitivity of the test and reduce the false assumption in heterogeneous distributed seed lots, sample intensity size is significant (Morrison 1999). Therefore, for testing seed lots, we used 20 subsets for all molecular testing. Using a binomial group testing methodology, this gives a theoretical incidence detection limit of $0.26 \%$, when each sample consists of 20 seeds (Gibbs and Gower 1960). These sample sizes and numbers were considered the best balance of practicality and incidence detection limits for our purposes.

As expected, there was a strong correlation between the conventional PCR and qPCR assays, but not with the seed wash assay and microscopic detection of oospores. DNA of one, or both, of the targeted Peronospora spp. were detected in all 20 samples tested by qPCR, 18/20 samples tested with conventional PCR, and 19/20 samples assessed with the seed wash method. The lack of correlation between the PCR assays and the seed wash data may be due to variability among the individual samples and replicates. For example, the total DNA found by qPCR ranged from 0.0 to $220.5 \mathrm{pg} / \mathrm{g}$ seed in sample SL22 and up to $50 \%$ of the 20 samples tested negative to both PCR and qPCR tests (Table 3). Similarly, Kunjeti et al. (2016) failed to find a ready correlation between microscopic observation and qPCR estimations of $P$. effus $a$ contamination of spinach seed. Our results indicated that variability within individual samples/replicates of individual seed lots may be present. High variability in the number of oospores per seed was observed in Peronospora farinose f. sp. chenopodii on quinoa (Danielsen et al. 2004), where the number of oospores on individual seeds ranged from 1 to 396 . Hence, it is possible that there was variation among replicates and seed samples of each line in our study. Additionally, the same DNA source of each seed lot sample was used for both PCR and qPCR, and these seed samples were separate and distinct from those used for the seed wash assay. This may further explain the lack of correlation for the two detection methods.

Successful transmission of both pathogens via an infested seed source to infected seedlings occurred at low frequency $(0.1$ to $0.05 \%)$. Low transmission rates are not uncommon for downy mildew species; seed transmission of $P$. farinosa $\mathrm{f}$. sp. chenopodii in quinoa and Hyaloperonospora parasitica in rapeseed mustard have both been recorded as less than 1\% (Danielsen et al. 2004; Vishunavat and Kolte 1993). It is also worth noting that transmission rate of Peronospora spp. can also be temperature dependent. Zimmer et al. (1992) observed that transmission rate of $P$. ducometi from buckwheat seed to seedlings was $35.9 \%$ at $14^{\circ} \mathrm{C}$, but only $1.3 \%$ at $25^{\circ} \mathrm{C}$. The optimum temperatures for $P$. somniferi and $P$. meconopsidis transmission from seed to seedling are currently unknown. Our data were from two trials and a single seed lot, and designed to confirm the occurrence of transmission only. The lack of observed symptoms in infected plants is likely due to glasshouse conditions suboptimal for disease expression. Subsequent glasshouse trials have shown the systemically infected stunted plants with sporulation in a low transmission rate, 7 out of 25 plants (unpublished data). Further testing would be required to more accurately determine transmission rates; however, this demonstrates the importance of seed inoculum for establishing foci of infection.

The PCR and qPCR assays described here quantify the pathogen in the seed lots and provide indication of risks associated with seedborne inoculum. They could also be useful for disease modeling, assessment of the efficacy of seed/fungicide control treatments, breeding for disease resistance, and host range and pathogen movement in the plants (Montes-Borrego et al. 2011; Thangavel et al. 2015).

\section{Acknowledgments}

This study was conducted under a Tasmanian Government license to cultivate a prohibited plant, license number 0785 . The authors declare that there is no conflict of interest.

\section{Literature Cited}

Adenle, V., and Cardwell, K. 2000. Seed transmission of maize downy mildew (Peronosclerospora sorghi) in Nigeria. Plant Pathol. 49:628-634.

Bustin, S. A., Benes, V., Garson, J. A., Hellemans, J., Huggett, J., Kubista, M., Mueller, R., Nolan, T., Pfaffl, M. W., and Shipley, G. L. 2009. The MIQE guidelines: Minimum information for publication of quantitative real-time PCR experiments. Clin. Chem. 55:611-622.
Clark, J. S. C., and Spencer-Phillips, P. T. N. 2004. The compatible interaction in downy mildew infections. Pages 1-34 in: Advances in Downy Mildew Research, Vol. 2. P. Spencer-Phillips and M. Jeger, eds. Springer Netherlands, Dordrecht.

Cohen, Y., Rubin, A. E., Galperin, M., Ploch, S., Runge, F., and Thines, M. 2014 Seed transmission of Pseudoperonospora cubensis. PLoS One 9:e109766.

Cotterill, P., and Pascoe, I. 1998. Downy mildew of Papaver somniferum in Tasmania. Australas. Plant Pathol. 27:263-264.

Danielsen, S., Mercado, V., Ames, T., and Munk, L. 2004. Seed transmission of downy mildew (Peronospora farinosa f. sp. chenopodii) in quinoa and effect of relative humidity on seedling infection. Seed Sci. Technol. 32:91-98.

Döken, M. T. 1989. Plasmopara halstedii (Farl.) Berl. et de Toni in sunflower seeds and the role of infected seeds in producing plants with systemic symptoms. J. Phytopathol. 124:23-26.

du Toit, L. J., and Hernandez-Perez, P. 2005. Efficacy of hot water and chlorine for eradication of Cladosporium variabile, Stemphylium botryosum, and Verticillium dahliae from spinach seed. Plant Dis. 89:1305-1312.

Fist, A. J., and Chung, B. 2015. Pyrethrum and poppy: Two Tasmanian industries of world significance. Acta Hortic.: 85-90.

Garibaldi, A., Minuto, G., Bertetti, D., and Gullino, M. L. 2004. Seed transmission of Peronospora sp. of Basil. Z. Pflanzenkr. Pflanzenschutz 111:465-469.

Gibbs, A., and Gower, J. 1960. The use of a multiple-transfer method in plant virus transmission studies some statistical points arising in the analysis of results. Ann. Appl. Biol. 48:75-83.

Guillemette, T., Iacomi-Vasilescu, B., and Simoneau, P. 2004. Conventional and real-time PCR-based assay for detecting pathogenic Alternaria brassicae in cruciferous seed. Plant Dis. 88:490-496.

Inaba, T., Takahashi, K., and Morinaka, T. 1983. Seed transmission of spinach downy mildew. Plant Dis. 67:1139-1141.

Jang, P., and Safeeulla, K. 1990. Modes of entry, establishment and seed transmission of Peronospora parasitica in radish. Proc. Indian Acad. Sci. Plant Sci. 100:369-373.

Kearse, M., Moir, R., Wilson, A., Stones-Havas, S., Cheung, M., Sturrock, S., Buxton, S., Cooper, A., Markowitz, S., and Duran, C. 2012. Geneious Basic: An integrated and extendable desktop software platform for the organization and analysis of sequence data. Bioinformatics 28:1647-1649.

Kunjeti, S. G., Anchieta, A., Subbarao, K. V., Koike, S. T., and Klosterman, S. J. 2016. Plasmolysis and vital staining reveal viable oospores of Peronospora effusa in spinach seed lots. Plant Dis. 100:59-65.

Landa, B. B., Montes-Borrego, M., Muñoz-Ledesma, F. J., and Jiménez-Díaz, R. M. 2007. Phylogenetic analysis of downy mildew pathogens of opium poppy and PCR-based in planta and seed detection of Peronospora arborescens. Phytopathology 97:1380-1390.

Levy, A., and Milo, J. 1998. Genetics and breeding of Papaver somniferum. Pages 114-126 in: Poppy: Poppy - The Genus Papaver. J. Bernath, ed. Hardwood Academic Publishers, Switzerland.

McGee, D. C. 1995. Epidemiological approach to disease management through seed technology. Annu. Rev. Phytopathol. 33:445-466.

McKay, R. 1957. The longevity of the oospores of onion downy mildew Peronospora destructor (Berk.) casp. Sci. Proc. R. Dublin Soc. 27:295-307.

Montes-Borrego, M., Ledesma, F. J. M., Jiménez-Díaz, R. M., and Landa, B. B. 2009. A nested-polymerase chain reaction protocol for detection and population biology studies of Peronospora arborescens, the downy mildew pathogen of opium poppy, using herbarium specimens and asymptomatic, fresh plant tissues. Phytopathology 99:73-81.

Montes-Borrego, M., Munoz-Ledesma, F., Jimenez-Diaz, R., and Landa, B. 2008 Peronospora arborescens causes downy mildew disease in commercial opium poppy crops in France. Plant Dis. 92:834.

Montes-Borrego, M., Muñoz-Ledesma, F. J., Jiménez-Díaz, R. M., and Landa, B. B. 2011. Real-time PCR quantification of Peronospora arborescens, the opium poppy downy mildew pathogen, in seed stocks and symptomless infected plants. Plant Dis. 95:143-152.

Morrison, R. 1999. Sampling in seed health testing. Phytopathology 89: 1084-1087.

Nega, E., Ulrich, R., Werner, S., and Jahn, M. 2003. Hot water treatment of vegetable seed-an alternative seed treatment method to control seed-borne pathogens in organic farming. J. Plant Dis. Prot. 3:220-234.

R Core Team. 2015. R: A language and environment for statistical computing V 3.1.0. R Foundation for Statistical Computing, Vienna, Austria.

Robideau, G. P., De Cock, A. W. A. M., Coffey, M. D., Voglmayr, H., Brouwer, H., Bala, H., Chitty, D., Desaulniers, N., and Eggertson, Q. A. 2011. DNA barcoding of oomycetes with cytochrome $\mathrm{c}$ oxidase subunit I and internal transcribed spacer. Mol. Ecol. Resour. 11:1002-1011.

Scott, J., Hay, F., Wilson, C., Cotterill, P., and Fist, A. 2003. Spatiotemporal analysis of epiphytotics of downy mildew of oilseed poppy in Tasmania, Australia. Phytopathology 93:752-757

Scott, J. B., Hay, F. S., and Wilson, C. R. 2004. Phylogenetic analysis of the downy mildew pathogen of oilseed poppy in Tasmania, and its detection by PCR Mycol. Res. 108:198-205.

Testen, A. L., del Mar Jiménez-Gasco, M., Ochoa, J. B., and Backman, P. A. 2014 Molecular detection of Peronospora variabilis in quinoa seed and phylogeny of the quinoa downy mildew pathogen in South America and the United States. Phytopathology 104:379-386. 
Thangavel, T., Tegg, R. S., and Wilson, C. R. 2015. Monitoring Spongospora subterranea development in potato roots reveals distinct infection patterns and enables efficient assessment of disease control methods. PLoS One 10: e0137647.

Thangavel, T., Wilson, C., Jones, S., Scott, J., and Voglmayr, H. 2017. First report of systemic downy mildew of opium poppy caused by Peronospora somniferi in Australia. Plant Dis. 101:392.

Vishunavat, K., and Kolte, S. 1993. Brassica seed infection with Peronospora parasitica (Pers. ex Fr.) Fr. and its transmission through seed. Indian J. Mycol. Plant Pathol. 23:247-249.

Voglmayr, H., Montes-Borrego, M., and Landa, B. B. 2014. Disentangling Peronospora on papaver: Phylogenetics, taxonomy, nomenclature and host range of downy mildew of opium poppy (Papaver somniferum) and related species. PLoS One 9:e96838.

Walcott, R. R. 2003. Detection of seedborne pathogens. HortTechnology 13 40-47.

White, J., Crute, I., and Wynn, E. 1984. A seed treatment for the control of Pythium damping-off diseases and Peronospora parasitica on brassicas. Ann. Appl. Biol. 104:241-247.

Yao, C., Frederiksen, R., and Magill, C. 1990. Seed transmission of sorghum downy mildew: Detection by DNA hybridisation. Seed Sci. Technol. 18:201-207.

Zimmer, R., McKeen, W., and Campbell, C. 1992. Location of oospores in buckwheat seed and probable roles of oospores and conidia of Peronospora ducometi in the disease cycle on buckwheat. J. Phytopathol. 135:217-223. 